Agron. Mesoam. 25(2):337-345. 2014

ISSN:2215-3608 doi 10.15517/am.v25i2.15441

\title{
USO DE AGROQUÍMICOS EN EL CULTIVO DE PAPA EN PACAYAS, CARTAGO, COSTA RICA ${ }^{1}$
}

\author{
Fernando Ramírez-Muñoz $z^{2}$, María Luisa Fournier-Leiva², Clemens Ruepert ${ }^{2}$, Carlos Hidalgo-Ardón ${ }^{3}$
}

\begin{abstract}
RESUMEN
Uso de agroquímicos en el cultivo de papa en Pacayas, Cartago, Costa Rica. El objetivo del presente trabajo fue realizar un diagnóstico de uso de plaguicidas y otros agroquímicos, a los productores de papa en Cartago, Costa Rica. Se emplearon cuestionarios de campo entre los años 2006 y 2009 en la microcuenca de las quebradas Plantón y Pacayas. Cada productor como promedio utilizó 32,8 kilogramos de ingrediente activo (i.a.) de plaguicida por hectárea por ciclo, en un rango de 10,9 a 88,3. Como uso ponderado por hectárea se calculó un valor de 42,6 kg i.a./ha/ciclo para plaguicidas y de $1879 \mathrm{~kg}$ de fertilizante formulado/ciclo. El grupo de mayor uso lo constituyeron los fungicidas-bactericidas con 30 i.a. y $85,7 \%$ del total de plaguicidas, le siguen los insecticidas (25 i.a. y $11,0 \%$ ) y los herbicidas (4 i.a. y 3,3\%). El agroquímico de mayor uso fue el mancozeb, seguido de propineb y clorotalonil; otros productos de alto empleo fueron fosetil aluminio, cartap, metamidofos, paraquat y endosulfan. Se utilizaron agroquímicos no registrados para papa y con reconocida toxicidad aguda y crónica. Los productores con mayor área cultivada adicionaron la mayor cantidad de plaguicida, mientras que en áreas menores el consumo fue menor pero se utilizó un mayor número de productos. Se utilizó más cantidad de plaguicidas y fertilizantes durante la época lluviosa de mayo a diciembre.
\end{abstract}

Palabras clave: plaguicidas en papa, fertilizantes, Solanum tuberosum.

\begin{abstract}
Use of agrochemicals in potato farming in Pacayas, Cartago, Costa Rica. The objective of this work was to produce a diagnostic of the use of pesticides and other agrochemicals by potato growers in Cartago, Costa Rica. The use of pesticides and fertilizers in potato fields of the Plantón Pacayas Watershed in Cartago, Costa Rica were diagnosed using field surveys, between 2006 and 2009. It was found that, on average, each farmer uses $32.8 \mathrm{~kg}$ of pesticide active ingredient per hectare per cycle ( $\mathrm{kg}$ ai/ha/cycle), in a wide range of 10.9 to $88.3 \mathrm{~kg}$. Weighted average pesticide use per hectare was found to be $42.6 \mathrm{~kg}$ ai/ha/cycle and $1879 \mathrm{~kg} /$ cycle of formulated fertilizers, representing a relatively high use compared to other intensive crops. The largest group used is fungicides-bactericides with 30 ai, representing $85.7 \%$ of all pesticides used, followed by insecticides (25 ai and $11.0 \%$ ) and herbicides (4 ai and 3.3\%). The most widely used pesticide is the fungicide mancozeb, come next by chlorothalonil and propineb; other high-use pesticides are fosetyl aluminum, cartap, methamidophos, endosulfan and paraquat. Unregistered and recognized toxic (acute and chronic toxicity) pesticides are used for potato production. Large area producers of potatoes use a higher quantity of pesticides, but use far less variety than smaller ones. More pesticides and fertilizers are during the rainy season from May to December.
\end{abstract}

Keywords: pesticides, fertilizers, Solanum tuberosum.

\footnotetext{
1 Recibido: 21 enero 2014. Aceptado: 30 de junio, 2014. Parte del proyecto marco "Mejoramiento de los sistemas de producción agropecuaria con tecnologías compatibles con el ambiente, zona piloto de estudio Plantón-Pacayas en la subcuenca del río Birrís, Costa Rica" del Instituto Nacional de Innovación y Transferencia en Tecnología Agropecuaria (INTA).

2 Instituto Regional de Estudios en Sustancias Tóxicas (IRET), Universidad Nacional. Apartado postal 86-3000 Heredia, Costa Rica. fernando. ramirez.munoz@una.cr,maria.fournier.leiva@una.cr, cruepert@gmail.com

3 Instituto Nacional de Innovación y Transferencia en Tecnología Agropecuaria (INTA). Apartado postal 382 Centro Colón, San José, Costa Rica.chidalgo@inta.go.cr
} 


\section{INTRODUCCCIÓN}

El cultivo de papa (Solanum tuberosum L.) a nivel mundial es una de las actividades agrícolas que consume más plaguicidas por unidad de área. En el noroeste de Estados Unidos, es la hortaliza con mayor cantidad usada por hectárea, con aplicaciones semanales o más frecuentes y la utilización de al menos 40 ingrediente activo (i.a.), entre estos: etoprofos, mancozeb, clorotalonil, EPTC y metribuzin (Murphy, 1997; Reuters, 2009). En los condados de mayor producción de papa en California, se reporta un uso de plaguicidas entre 8,88 y $26,76 \mathrm{~kg}$ i.a./ha/ciclo, y un valor promedio de uso para el Estado de 7,09 kg i.a./ ha/ciclo (PAN, 2007). En otro estudio llevado a cabo en Ecuador, Crissman et al. (2003) encontraron que los productores de papa utilizaban 24 i.a. de diferentes de fungicidas, de los cuales el mancozeb representaba el $80 \%$ del total.

Este alto uso de plaguicidas se debe a que el cultivo de papa está expuesto al ataque de numerosas plagas, patógenos y malezas, la mayoría de las cuales se incrementan en condiciones de alta humedad. Su producción en monocultivo siempre ha estado ligada a una alta dependencia de plaguicidas y fertilizantes. Según CIP y FAO (2008), el uso de plaguicidas químicos en la papa está aumentando en los países en desarrollo, conforme los agricultores intensifican la producción y empiezan a producir en zonas y en temporadas no tradicionales para este cultivo. Varias de las sustancias químicas usadas con frecuencia son muy tóxicas y se aplican con insuficiente o ningún equipo de protección del trabajador.

A nivel nacional, la papa es la hortaliza de mayor importancia, por la actividad económica asociada a su producción, por su área cultivada y por el consumo o aporte a la dieta nacional (Bolaños, 2007; Montero et al., 2007). En el año 2010 se registró una producción de $55711 \mathrm{t}$, proveniente de 2233 hectáreas cultivadas por un grupo aproximado de 1200 productores y con un rendimiento promedio de $25 \mathrm{t} / \mathrm{ha}$, aunque con una disminución del 25,1\% del área de cultivo con respecto al año anterior (SEPSA, 2011).

La principal zona productora de papa del país se encuentra en la parte norte de la provincia de Cartago en las faldas de los volcanes Irazú y Turrialba, con cerca del 75,2\% del área total cultivada; el resto del área $(24,2 \%)$ se localiza en la zona de Zarcero en la provincia de Alajuela (SEPSA, 2011). La región productora de papa para semilla se concentra en las tierras altas y fértiles cercanas al volcán Irazú, donde el clima es más frío y por lo tanto hay menor presión de plagas (Vásquez, 2005). Para el 2010, según datos de SEPSA (2011), hubo un rendimiento promedio de $25 \mathrm{t} / \mathrm{ha}$. El consumo nacional de papa ha pasado de 12,2 a $20,8 \mathrm{~kg}$ per cápita/año entre los años 2009 a 2012 y es cercano a las $70000 \mathrm{t}$ anuales (PIMA, 2013).

El uso de plaguicidas en Costa Rica para el año 2006, se estimó en 19,33 kg i.a./ha/año (Ramírez et al., 2009), y es uno de los mayores consumos por unidad de área a nivel mundial. El uso de plaguicidas promedio en papa para el año 1998 (Chaverri et al., 2000), con base en avíos bancarios, es de $37,32 \mathrm{~kg}$ i.a./ ha/ciclo y según encuestas a productores de $38,75 \mathrm{~kg}$ i.a./ha/ciclo.

El objetivo de este estudio fue diagnosticar el uso de plaguicidas y fertilizantes en el cultivo de papa en Cartago, Costa Rica.

\section{METODOLOGÍA}

Entre los años 2006 y 2009 se aplicaron 136 cuestionarios estructurados con preguntas cerradas y abiertas, a productores hortícolas de la zona norte de Cartago, cuyos cultivos abarcaron 89 ha de las 180 ha de hortalizas y de las 560 ha de la microcuenca de las quebradas Plantón y Pacayas; de estas entrevistas, 52 fueron hechas a 44 productores de papa. Esa microcuenca está localizada a una altitud de 1720 a 2900 msnm, la precipitación anual varía de 1773 a $2228 \mathrm{~mm}$, la temperatura promedio de 14,1 a $16,7^{\circ} \mathrm{C}$ y la humedad relativa de 81 a $88 \%$ (Gómez, 2004).

Se recolectaron datos sobre uso cronológico de plaguicidas, fertilizantes y enmiendas, nombres comerciales, formulaciones, dosis, descarga, área aplicada, fecha de siembra, origen de la semilla, forma de manejar el terreno, frecuencia de aplicación en las diferentes etapas del ciclo de producción, desde fases iniciales de almacenaje de semilla, vivero, preparación de terreno hasta poscosecha y transporte, tiempo entre última aplicación y cosecha, y alternancia con otros cultivos.

El uso total de plaguicidas se expresa en $\mathrm{kg}$ i.a./ha por ciclo de cultivo, y se presenta como el promedio de uso por productor y el promedio ponderado de uso por cada hectárea cultivada en la zona de estudio. El promedio ponderado de uso por hectárea se 
calcula multiplicando la cantidad de plaguicida que el productor usa en cada hectárea por el área donde aplicó ese plaguicida; las cifras obtenidas se suman y el resultado se divide entre el área total cultivada por esos productores. Este promedio ponderado da una idea más real de la cantidad de plaguicidas aplicados en cada hectárea de cultivo:

\section{Promedio de Uso Ponderado $=\sum(\mathrm{kg}$ i.a./ha * área $) /$ $\Sigma$ hectáreas cultivadas}

De acuerdo con su acción biocida, los plaguicidas se clasificaron en tres grupos: 1- fungicidas (incluye bactericidas y antibióticos), 2- insecticidas (incluye nematicidas y acaricidas) y 3- herbicidas. Además, se comparó el uso de plaguicidas y fertilizantes en dos épocas del año, el periodo seco de enero a mayo, y el lluvioso de junio a diciembre. También se determinó el uso de acuerdo al área de producción, para separar agrupándolos en grandes productores ( 3 a 21 ha/ciclo) y pequeños productores (menos de $2,1 \mathrm{ha} /$ ciclo). El uso de fertilizantes se expresa como la sumatoria del peso de los fertilizantes formulados, granulados y líquidos; para estos últimos se estimó equivalente 1 litro a $1 \mathrm{~kg}$. Además, se estimó el aporte de nitrógeno $\mathrm{y}$ fósforo del total de fertilizantes.

\section{RESULTADOS Y DISCUSIÓN}

Los agricultores de papa representaron el 60\% de 74 productores de hortalizas identificados durante los tres años en la zona de estudio. Del total de 136 cuestionarios realizados a horticultores, 52 correspondieron a cultivos de papa; algunos de los productores de papa fueron entrevistados más de una vez en el periodo de muestreo. Al igual que otros cultivos de la zona como brócoli, coliflor, zanahoria y repollo, la mayoría de las fincas de papa son parcelas pequeñas $(\geq 0,18<2,1$ ha) en terreros cuyas pendientes varían de onduladas (15$30 \%)$, fuertemente onduladas (30-50\%) y escarpadas (50-75\%). La primera categoría corresponde al 30,95\% del área de la microcuenca, la segunda al 43,6\% y la última al 18\% (Arroyo et al., 2006).

\section{Manejo general del cultivo}

En la zona Plantón-Pacayas, la papa se siembra durante todo el año, la mayoría en dos épocas, una de diciembre a febrero y otra de junio a agosto. Los productores por lo general almacenan en la oscuridad semilla (vegetativa) del ciclo anterior, tratándola con insecticidas y fungicidas para evitar daño por polilla y pudriciones. En la preparación inicial del terreno, la maleza se elimina con herbicidas glifosato o paraquat, luego mediante tracción animal o mecánica, se ara y alomilla el suelo y se ponen las enmiendas, usualmente cal. Al momento de la siembra, se aplica junto a la semilla insecticidas, nematicidas granulados, bactericidas y fungicidas, así mismo el fertilizante granulado. Una vez germinado el tubérculo, comienza la secuencia de atomizaciones con un insecticida y un fungicida. Posteriormente, se realizan aplicaciones regulares cada semana con fungicidas y abonos foliares, intercaladas con dos a tres atomizaciones de insecticidas y la aplicación de un fertilizante granulado al momento de la aporca; las aplicaciones son mezclas de varios plaguicidas y fertilizantes foliares. El ciclo termina con una aplicación de un herbicida quemante (paraquat) para eliminar el follaje, de una a cuatro semanas antes de la cosecha, tiempo muy influenciado por el precio de mercado.

La papa recibe un tratamiento de lavado poscosecha, tanto para el mercado local e internacional, y se desecha una gran cantidad de agua con sedimento en los sistemas de alcantarillado o quebradas. En la zona se acostumbra hacer dos ciclos al año o la combinación de un ciclo de papa con uno o dos de otros cultivos como zanahoria, repollo, brócoli, coliflor o remolacha.

\section{Uso total de plaguicidas}

La cantidad de plaguicida utilizado en el cultivo de papa, muestra una relación directa con el número de aplicaciones efectuadas por cada productor durante el ciclo de cultivo (frecuencia), con la dosis y con el número de ingredientes activos (i.a.) usados en cada fumigación (mezclas). La cantidad aplicada se ve afectada por el uso de métodos no químicos para el control de plagas, como la mecanización en vez de herbicidas para preparar el terreno, trampas para insectos para reducir el uso de insecticidas, uso de bioplaguicidas y corte de la planta con machete en lugar de herbicidas para desecar la planta antes de la cosecha.

Al considerar todas las etapas del ciclo de cultivo de papa: almacenamiento de semilla, preparación de terreno, mantenimiento y cosecha, los productores 
en promedio aplican 16,8 veces, con un rango entre 11 a 26 veces en un ciclo de cultivo de 3,5 a 5 meses de duración; esto depende de la altitud, el manejo agronómico y el precio de demanda en el momento cercano a la cosecha. En el principal periodo de atomizaciones (mantenimiento) de alrededor ocho semanas se hacen de 7 a 22 aplicaciones, es decir, 1 a 2,7 veces por semana.

En promedio cada productor utilizó $32,8 \mathrm{~kg}$ i.a./ ha/ciclo, en un ámbito de uso muy amplio de 10,9 a $88,3 \mathrm{~kg}$ i.a./ha/ciclo y representado por las barras en las columnas, indicadoras de los valores máximos y mínimos encontrados en las 52 encuestas realizadas (Figura 1). Sin embargo, cuando estos datos de uso se ponderan por cantidad de hectáreas, se encuentra un promedio de uso ponderado para cada hectárea cultivada con papa en la microcuenca Plantón-Pacayas de 42,6 kg i.a./ha/ciclo, obviamente con valores más altos si se cultivan dos ciclos por año. Esto representa un uso relativo muy grande si se compara con otros cultivos agrícolas de Costa Rica de alto uso de plaguicidas, como piña o banano, que poseen usos anuales de entre 30 a $50 \mathrm{~kg}$ i.a/ha/año (Bravo et al., 2013).

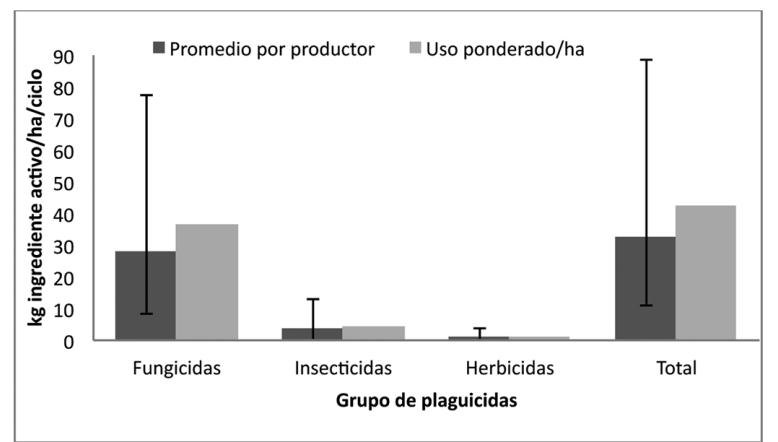

Figura 1. Ámbito de uso de plaguicidas por acción biocida en el cultivo de papa en la zona de Pacayas, Cartago, Costa Rica. 2006-2009.

Al igual que en otros países, el grupo de los fungicidas/bactericidas son de mayor uso en la producción de papa, con un total de 30 i.a. diferentes (Cuadro 1). El 98,1\% de los productores aplica mancozeb, 88,5\% clorotalonil, 76,9\% cimoxanil y $65,4 \%$ propineb. Esto concuerda con Chaverri et al. (2000) donde muestran a los fungicidas como el principal grupo $(75$ y $69 \%$ para avíos bancarios y encuestas a productores), seguido por los insecticidas (24 y $28 \%$ ) y los herbicidas (1 y $3 \%$ ) respectivamente.

Los insecticidas representan el $11 \%$ del total de plaguicidas usados con 25 i.a. distintos (Cuadro 2), dentro de los cuales destacan, por porcentaje de usuarios, foxim (lo usa el 79\% de los productores), clorpirifos (67\%) y deltametrina (46\%). Los principales insecticidas usados, por cantidad, son cartap $(2,5 \%$ del total de plaguicidas) clorpirifos $(2,0 \%)$ y metamidofos $(1,2 \%)$; estos tres últimos conforman el $52 \%$ de la cantidad de insecticidas usados en papa. De los 4 i.a. de herbicidas usados (3,3\% del total de plaguicidas), el paraquat es utilizado por el $96 \%$ de los productores, representa el $1,75 \%$ del total de plaguicidas y el $53 \%$ de los herbicidas.

\section{Uso de fungicidas y bactericidas}

La totalidad de los productores de papa utiliza fungicidas en su paquete de insumos. Cada productor aplica entre 1 y 12 i.a. diferentes por ciclo de cultivo, con un promedio de 6,4. Los fungicidas de mayor uso por hectárea son mancozeb, propineb, clorotalonil y fosetil aluminio, tanto de acción protectante como sistémica, representan el $77 \%$ del total de plaguicidas y el $90 \%$ de los fungicidas (Cuadro 1). De acuerdo a las cifras de tolerancia o Límites Máximos de Residuos (LMR) utilizados en Costa Rica (SFE, 2012), algunas formulaciones de fungicidas no están permitidos en papa, pues no se conocen sus valores de LMR. En la zona de estudio, se utilizan cuatro fungicidas bajo estas condiciones: boscalid, carboxin, ciproconazole, cloroneb y dos antibióticos: kasugamicina y validamicina.

Varios fungicidas de uso en la zona, clorotalonil, captan, PCNB (organoclorado), ciproconazol e incluso mancozeb, el más utilizado, han sido clasificados por la Agencia de Protección Ambiental de EE.UU. (EPA), la Agencia Internacional de Investigación en Cáncer (IARC) y la Unión Europea (EU), como con suficiente evidencia en animales y posiblemente en humanos, de producir cáncer o de causar efectos irreversibles en la salud (PAN-UK, 2009). También los fungicidas mancozeb, ziram, propineb, carboxin y carbendazina han demostrado tener efectos sobre el desarrollo o la reproducción del ser humano y los dos primeros son sustancias reconocidas de causar disrupción endocrina (PAN, sf; PAN-UK, 2009). 
Cuadro 1. Uso de fungicidas y bactericidas (kg i.a./ha/ciclo) en el cultivo de papa en la zona de Pacayas, Cartago, Costa Rica. 20062009.

\begin{tabular}{|c|c|c|c|c|c|c|}
\hline \multirow[t]{2}{*}{ Plaguicida } & \multirow{2}{*}{$\begin{array}{c}\text { Uso } \\
\text { ponderado/ha }\end{array}$} & \multicolumn{3}{|c|}{ Uso por productor } & \multirow{2}{*}{$\begin{array}{c}\% \text { de total } \\
\text { plaguicidas }\end{array}$} & \multirow{2}{*}{$\begin{array}{c}\% \\
\text { de usuarios } \\
\end{array}$} \\
\hline & & Promedio & Mínimo* & Máximo & & \\
\hline Azoxistrobina & 0,0005 & 0,14 & 0,14 & 0,14 & 0,001 & 1,92 \\
\hline Boscalid & 0,0166 & 2,16 & 2,16 & 2,16 & 0,039 & 1,92 \\
\hline Captan & 0,1967 & 1,14 & 0,10 & 11,43 & 0,462 & 28,85 \\
\hline Carbendazina & 0,2596 & 2,47 & 0,27 & 10,92 & 0,610 & 25,00 \\
\hline Carboxin** & 0,1330 & 0,28 & 0,10 & 0,57 & 0,313 & 19,23 \\
\hline Cimoxanil & 0,6754 & 0,54 & 0,06 & 1,83 & 1,587 & 76,92 \\
\hline Ciproconazol & 0,0003 & 0,05 & 0,05 & 0,05 & 0,001 & 1,92 \\
\hline Cloroneb & 0,0071 & 0,93 & 0,93 & 0,93 & 0,017 & 1,92 \\
\hline Clorotalonil & 6,4094 & 8,63 & 1,00 & 32,59 & 15,059 & 88,46 \\
\hline Dimetomorf & 0,2255 & 0,43 & 0,08 & 1,34 & 0,530 & 46,15 \\
\hline Estreptomicina & 0,0037 & 0,48 & 0,48 & 0,48 & 0,009 & 1,92 \\
\hline Famoxadona & 0,0051 & 0,12 & 0,02 & 0,23 & 0,012 & 3,85 \\
\hline Fenamidona & 0,0155 & 0,28 & 0,10 & 0,74 & 0,036 & 13,46 \\
\hline Flutolanil & 0,1538 & 0,98 & 0,33 & 2,75 & 0,361 & 28,85 \\
\hline Fosetil aluminio & 4,3363 & 5,20 & 0,80 & 18,29 & 10,188 & 9,62 \\
\hline Iprovalicarb & 0,0219 & 0,42 & 0,10 & 0,84 & 0,051 & 15,38 \\
\hline Kasugamicina & 0,0009 & 0,04 & 0,04 & 0,04 & 0,002 & 1,92 \\
\hline Mancozeb & 13,1417 & 10,62 & 0,89 & 49,14 & 30,877 & 98,08 \\
\hline Metalaxil & 0,0030 & 0,51 & 0,51 & 0,51 & 0,007 & 1,92 \\
\hline Oxicloruro cobre & 0,2342 & 0,49 & 0,22 & 0,90 & 0,550 & 7,69 \\
\hline Oxitetraciclina & 0,0004 & 0,05 & 0,05 & 0,05 & 0,001 & 1,92 \\
\hline $\mathrm{PCNB} * *$ & 0,6103 & 6,96 & 1,88 & 15,00 & 1,434 & 23,08 \\
\hline Pencicuron** & 0,0853 & 0,59 & 0,06 & 1,00 & 0,200 & 28,85 \\
\hline Propamocarb & 0,0912 & 0,85 & 0,48 & 1,55 & 0,214 & 13,46 \\
\hline Propineb & 8,8855 & 7,66 & 1,05 & 20,00 & 20,877 & 65,38 \\
\hline Piraclostrobina & 0,0084 & 1,10 & 1,10 & 1,10 & 0,020 & 1,92 \\
\hline ТСМТВ & 0,0809 & 1,03 & 0,45 & 1,80 & 0,190 & 5,77 \\
\hline Tolclofos metil** & 0,6833 & 1,31 & 0,05 & 2,86 & 1,605 & 11,54 \\
\hline Validamicina & 0,0027 & 0,12 & 0,12 & 0,12 & 0,006 & 1,92 \\
\hline Ziram & 0,1936 & 5,73 & 1,52 & 9,77 & 0,455 & 9,62 \\
\hline Total & 36,48 & 28,36 & 8,21 & 77,43 & 85,71 & 100 \\
\hline
\end{tabular}

* El valor mínimo corresponde a la cantidad de plaguicida cuando este es utilizado.

** Por lo general, se aplican solo una vez durante el ciclo de cultivo.

\section{Uso de insecticidas y herbicidas}

El total de los productores de papa en la zona de Pacayas aplican insecticidas y representan el 11\% del total de los plaguicidas usados (Cuadro 2). Cada agricultor usa entre 1 y 9 i.a. de insecticidas por ciclo, con un promedio de 4,6 y los más usados son foxim $(78,9 \%)$, clorpirifos $(38,5 \%)$, ciromazina $(36,5 \%)$ 
Cuadro 2. Uso de insecticidas y herbicidas (kg i.a./ha/ciclo) en el cultivo de papa en la zona de Pacayas, Cartago, Costa Rica. 20062009.

\begin{tabular}{|c|c|c|c|c|c|c|}
\hline \multirow[t]{2}{*}{ Plaguicidas } & \multirow{2}{*}{$\begin{array}{c}\text { Uso } \\
\text { ponderado/ha }\end{array}$} & \multicolumn{3}{|c|}{ Uso por productor o parcela } & \multirow{2}{*}{$\begin{array}{c}\text { \% del total de } \\
\text { plaguicidas }\end{array}$} & \multirow{2}{*}{$\begin{array}{c}\% \\
\text { de usuarios }\end{array}$} \\
\hline & & Promedio & Mínimo* & Máximo & & \\
\hline \multicolumn{7}{|l|}{ Insecticidas } \\
\hline Abamectina & 0,0076 & 0,02 & 0,004 & 0,031 & 0,018 & 13,46 \\
\hline Acefato** & 0,0552 & 0,91 & 0,750 & 1,071 & 0,130 & 3,85 \\
\hline Aldicarb & 0,0247 & 4,50 & 4,500 & 4,500 & 0,058 & 1,92 \\
\hline Carbofuran $* *$ & 0,1033 & 1,38 & 0,686 & 2,300 & 0,243 & 5,77 \\
\hline Cartap & 1,0707 & 1,38 & 0,143 & 4,286 & 2,516 & 11,54 \\
\hline Cipermetrina & 0,0120 & 0,22 & 0,020 & 0,857 & 0,028 & 17,31 \\
\hline Ciromazina & 0,0518 & 0,39 & 0,050 & 1,714 & 0,122 & 38,46 \\
\hline Clorpirifos & 0,8483 & 1,95 & 0,343 & 10,285 & 1,993 & 67,31 \\
\hline Deltametrina & 0,0082 & 0,02 & 0,003 & 0,106 & 0,019 & 46,15 \\
\hline Diazinon & 0,0053 & 0,24 & 0,240 & 0,240 & 0,012 & 1,92 \\
\hline Dimetoato & 0,0385 & 0,60 & 0,214 & 1,714 & 0,090 & 15,38 \\
\hline Endosulfan & 0,4766 & 1,01 & 0,263 & 2,000 & 1,120 & 11,54 \\
\hline Etion & 0,0247 & 1,11 & 0,714 & 1,500 & 0,058 & 3,85 \\
\hline Fenamifos & 0,0330 & 2,00 & 2,000 & 2,000 & 0,077 & 1,92 \\
\hline Forato & 0,3145 & 2,07 & 0,500 & 3,571 & 0,739 & 25,00 \\
\hline Foxim** & 0,3518 & 0,27 & 0,004 & 4,000 & 0,827 & 78,85 \\
\hline Lambda cihalotrina** & 0,0014 & 0,02 & 0,003 & 0,071 & 0,003 & 17,31 \\
\hline Metamidofos & 0,4880 & 0,75 & 0,180 & 2,400 & 1,146 & 36,54 \\
\hline Metil paration & 0,0303 & 0,71 & 0,343 & 1,440 & 0,071 & 5,77 \\
\hline Novaluron & 0,0003 & 0,05 & 0,047 & 0,047 & 0,001 & 1,92 \\
\hline Oxamil & 0,0632 & 0,78 & 0,514 & 1,371 & 0,149 & 7,69 \\
\hline Permetrina & 0,0281 & 0,66 & 0,050 & 4,286 & 0,066 & 17,31 \\
\hline Protiofos & 0,2175 & 0,54 & 0,250 & 0,875 & 0,511 & 13,46 \\
\hline Tiociclam hidrogenoxalato & 0,4217 & 1,02 & 0,125 & 2,271 & 0,991 & 9,62 \\
\hline Zeta cipermetrina & 0,0014 & 0,10 & 0,069 & 0,129 & 0,003 & 3,85 \\
\hline Total insecticidas & 4,68 & 3,57 & 0,054 & 12,913 & 10,99 & 100 \\
\hline \multicolumn{7}{|l|}{ Herbicidas } \\
\hline Glifosato** & 0,311 & 0,70 & 0,089 & 1,424 & 0,730 & 19,23 \\
\hline Linuron** & 0,343 & 0,98 & 0,714 & 1,429 & 0,807 & 7,69 \\
\hline Metribuzin** & 0,003 & 0,34 & 0,343 & 0,343 & 0,006 & 1,92 \\
\hline Paraquat & 0,746 & 0,66 & 0,080 & 1,524 & 1,752 & 96,15 \\
\hline Total herbicidas & 1,40 & 0,87 & 0,080 & 3,59 & 3,30 & 98,00 \\
\hline
\end{tabular}

* El valor mínimo corresponde a la cantidad de plaguicida cuando este es utilizado.

** Por lo general, se aplican solo una vez durante el ciclo de cultivo.

y metamidofos $(36,5 \%)$. Los insecticidas de mayor uso ponderado por hectárea son cartap, clorpirifos, metamidofos y endosulfan (organoclorado), todos con características de alta toxicidad (De la Cruz et al., 2010).
Los herbicidas son los plaguicidas de menor uso relativo en la zona de estudio, tanto en cantidad como en variedad, usados en su mayoría una o dos veces por ciclo. Cada productor utiliza entre 0 y 3 i.a. diferentes de herbicidas por ciclo, con un promedio 
de 1,3. El herbicida más empleado es el paraquat y la mayor parte se aplica para desecar la planta antes de la cosecha; seguido por glifosato para preparar el terreno antes de la siembra, linuron y metribuzin, este último lo usó solamente un productor durante los tres años de duración del presente estudio. Tanto linuron como metribuzin tienen efectos toxicológicos sobre el desarrollo y la reproducción del ser humano, además se consideran disruptores endocrinos (PAN, sf; PANUK, 2009).

\section{Uso por tamaño de la explotación}

En la zona de Pacayas se pueden clasificar dos tipos de productores de papa. Los grandes, los cuales representan el $12 \%$ de los encuestados y el 57\% del área de papa, con explotaciones entre 3 y 21 ha por ciclo (11,7 ha promedio) dedicadas a producir semilla y localizadas en la parte de mayor altitud. Los pequeños, con explotaciones entre 0,18 y 2,1 ha por ciclo ( 0,90 ha promedio), cultivadas por el $88 \%$ de los encuestados, representan el $43 \%$ del área de papa y están ubicadas en la parte media y baja de la microcuenca. Los dos agricultores de papa con mayor uso de plaguicida por ciclo ( 86,0 y $88,3 \mathrm{~kg}$ i.a./ha) se dedican a la producción de semilla vegetativa; están a la altura de Cerro Gurdián en la ruta al volcán Irazú y siembran las fincas más extensas (28\% del área encuestada de papa y $48 \%$ del área de grandes productores), y por lo común tienen un solo ciclo de cultivo al año durante la época lluviosa.

Las unidades de cultivo grandes suman 50,6 ha, con un promedio de uso por productor de $50,58 \mathrm{~kg}$ i.a./ha/ciclo y un promedio ponderado de uso por cada hectárea cultivada de $54,70 \mathrm{~kg}$ i.a./ha/ciclo. En total se aplicaron 31 i.a. diferentes, de los cuales el $48 \%$ lo repesentan quince insecticidas, siendo los de mayor uso foxim y metamidofos; el $42 \%$ lo conforman trece fungicidas, destacándose mancozeb y cimoxamil; y el $10 \%$ correspondientes a tres herbicidas, siendo los principales paraquat y glifosato.

El área de las unidades de cultivo pequeñas suma 38,5 ha, representaron el $43 \%$ del total del área encuestada y utilizaron cantidades de plaguicida menores, con un uso promedio por productor de $30,45 \mathrm{~kg}$ i.a./ha/ciclo y $27,38 \mathrm{~kg}$ i.a./ha/ciclo de promedio ponderado por cada hectárea cultivada. Los pequeños productores fumigan con 58 i.a. diferentes:
25 insecticidas (43\%), en especial foxim y clorpirifos; 29 fungicidas (50\%), en su mayoría mancozeb y clorotalonil, y 4 herbicidas, los principales paraquat y glifosato (7\%).

El alto uso de plaguicidas en las fincas grandes productoras de semilla en los sectores de más altitud en la microcuenca, representa un impacto potencial sobre el recurso hídrico disponible para abastecer las comunidades aguas abajo.

\section{Uso de agroquímicos por época climática}

Se comparó el uso de plaguicidas y fertilizantes en las dos épocas del año, la seca entre enero y abril y la lluviosa de mayo a diciembre. Los productores de papa cultivan más sus tierras en la estación de lluvias (30 productores) que en el verano (12), otros lo hacen en ambas (10). También durante la época lluviosa se aplica más del doble del promedio ponderado de plaguicida por hectárea (Cuadro 3). Contribuyen la incidencia fuerte de enfermedades fungosas durante esa época y el cultivo de la mayor parte de los productores grandes en la estación de lluvias, en ciclos largos para la producción de semilla y por lo tanto, usan cantidades importantes de plaguicidas.

\section{Uso de fertilizantes}

Los fertilizantes químicos son asimismo un insumo muy utilizado en la producción de papa en la zona de estudio. Los principales fertilizantes aplicados son las fórmulas comerciales 10-30-10, 12-24-12, 194-19, 15-15-15, 12-30-8 y numerosos de tipo foliar con macro y microelementos. Se determinó un promedio de uso de fertilizante formulado, granulado o líquido, de $1600 \mathrm{~kg} / \mathrm{ha} /$ ciclo con un rango de 566 a $3021 \mathrm{~kg} /$ ha/ciclo y un promedio ponderado por hectárea de $1879 \mathrm{~kg}$ de fertilizante por ciclo; se aplica alrededor de $20 \%$ menos en la estación lluviosa. Los datos de uso de fertilizante indican valores superiores a los recomendados para papa por Pumisacho y Velásquez (2009) de cerca de 900 a $1200 \mathrm{~kg}$ de fertilizante granulado/ha o cercanos a los recomendados por MAG (1991) de $1000 \mathrm{~kg} / \mathrm{ha}$ de la fórmula 10-30-10 para suelos con contenidos altos o medios de fósforo, o de $2000 \mathrm{~kg} / \mathrm{ha}$ para suelos pobres en este elemento.

De acuerdo con los promedios de uso de fertilizantes, se estimó la aplicación de nitrógeno al 
Cuadro 3. Principales plaguicidas y fertilizantes (kg i.a./ha/ciclo) usados en papa por estación climática en la zona de Pacayas, Cartago, Costa Rica. 2006-2009.

\begin{tabular}{|c|c|c|c|c|c|c|c|c|c|c|c|c|}
\hline & \multicolumn{6}{|c|}{ Época seca } & \multicolumn{6}{|c|}{ Época lluviosa } \\
\hline & $\begin{array}{l}\text { Prome- } \\
\text { dio/ pro- } \\
\text { ductor* }\end{array}$ & $\begin{array}{l}\text { Prome- } \\
\text { dio pon- } \\
\text { derado/ } \\
\text { ha* }\end{array}$ & $\begin{array}{l}\mathrm{N}^{\circ} \\
\text { i.a. }\end{array}$ & $\begin{array}{l}\text { \% uso / } \\
\text { acción } \\
\text { biocida }\end{array}$ & $\begin{array}{c}\text { Principales } \\
\text { plaguicidas } \\
\text { usados }\end{array}$ & $\begin{array}{c}\% \text { de } \\
\text { total } \\
\text { plagui- } \\
\text { cidas }\end{array}$ & $\begin{array}{l}\text { Prome- } \\
\text { dio/pro- } \\
\text { ductor * }\end{array}$ & $\begin{array}{l}\text { Prome- } \\
\text { dio pon- } \\
\text { derado/ } \\
\text { ha* }\end{array}$ & $\begin{array}{l}\mathrm{N}^{\circ} \\
\text { i.a. }\end{array}$ & $\begin{array}{l}\text { \% uso/ } \\
\text { acción } \\
\text { biocida }\end{array}$ & $\begin{array}{l}\text { Principa- } \\
\text { les pla- } \\
\text { guicidas } \\
\text { usados }\end{array}$ & $\begin{array}{c}\% \text { de } \\
\text { total } \\
\text { plagui- } \\
\text { cidas }\end{array}$ \\
\hline \multirow[t]{3}{*}{ Insecticidas } & 3,87 & 1,9 & 19 & 9,4 & clorpirifos & 4,4 & 3,72 & 5,92 & 23 & 11,4 & cartap & 2,8 \\
\hline & & & & & metamidofos & 1,1 & & & & & clorpirifos & 1,6 \\
\hline & & & & & ciromazina & 0,5 & & & & & endosulfan & 1,3 \\
\hline \multirow[t]{3}{*}{ Fungicidas } & 23,62 & 17,8 & 20 & 87,6 & propineb & 34 & 29,92 & 44,14 & 23 & 85,2 & mancozeb & 30 \\
\hline & & & & & mancozeb & 27 & & & & & propineb & 19 \\
\hline & & & & & clorotalonil & 17 & & & & & clorotalonil & 14 \\
\hline \multirow[t]{2}{*}{ Herbicidas } & 0,81 & 0,6 & 3 & 3,0 & paraquat & 2,5 & 0,93 & 1,76 & 4 & 3,4 & paraquat & 1,6 \\
\hline & & & & & glifosato & 0,4 & & & & & linuron & 1,0 \\
\hline $\begin{array}{l}\text { Total } \\
\text { plaguicidas }\end{array}$ & 28,31 & 20,3 & 42 & & & & 34,58 & 51,82 & 50 & & & \\
\hline Fertilizantes* & 1579 & 2140 & & & & & 1691 & 1879 & & & & \\
\hline
\end{tabular}

*Producto formulado en $\mathrm{kg} / \mathrm{ha} / \mathrm{ciclo}$.

cultivo entre 320 a $375 \mathrm{~kg} / \mathrm{ha}$ y de 275 a $325 \mathrm{~kg}$ de fósforo/ha, lo que según MAG (1991), para nitrógeno es un valor muy por encima de lo recomendado para el cultivo de la papa, pero para fósforo es un valor normal recomendado. Por este motivo, es necesaria una adecuada fertilización dependiendo de las características físico químicas del suelo y de las necesidades del cultivo, para evitar una dosis que vaya a causar problemas de contaminación de aguas, especialmente por nitratos y nitritos, y que impactan directamente a los costos de producción.

Así mismo, debido al alto uso de agroquímicos en el cultivo, se deben de implementar alternativas de menor impacto hacia la salud de los habitantes $y$ al ambiente en general, que logren mantener una producción económicamente rentable para los productores y de forma sostenible.

\section{LITERATURA CITADA}

Arroyo, L., M. Ugalde, y E. Araya. 2006. Línea base biofísica y técnico productiva para la intervención y desarrollo de la actividad productiva en la microcuenca PlantónPacayas. Documento Técnico N² 2. Proyecto Plantón
Pacayas. INTA-MAG Instituto Nacional de Innovación y Transferencia en Tecnología Agropecuaria, San José. Bolaños, A. 2007. Introducción a la olericultura. EUNED, San José, Costa Rica.

Bravo, V., E. de la Cruz, G. Herrera, y F. Ramírez. 2013. Uso de plaguicidas en cultivos agrícolas como herramienta para el monitoreo de peligros en salud. Uniciencia 27(1):351-376.

CIP (Centro Internacional de la Papa) y FAO. 2008. Gestión de plagas y enfermedades de la papa. http://www.fao. org/Potato-2008/es/lapapa/IyP-5es.pdf (Consultado 29 enero 2012).

Chaverri, F., L. Soto, F. Ramírez, y V. Bravo. 2000. Diagnóstico preliminar del uso de plaguicidas en los cultivos de arroz, banano, café, caña de azúcar, cebolla, melón, naranja, papa, piña, tomate, flores y plantas ornamentales. Programa SAREC de Investigación en ambiente y salud en Centro América, Instituto Regional de Estudios en Sustancias Tóxicas (IRET), Universidad Nacional, Heredia, Costa Rica.

Crissman, C., P. Espinosa, y V.H. Barrera. 2003. El uso de plaguicidas en la producción de papa en Carchí. En: CIP-INIAP, editor, Los plaguicidas: impactos en producción, salud y medio ambiente en Carchí, Ecuador. p. 9-24. Carchí, Ecuador. 
De la Cruz, E., V. Bravo, y F. Ramírez. 2010. Manual plaguicidas de Centroamérica. Instituto Regional de Estudios en Sustancias Tóxicas, Universidad Nacional. Costa Rica. http://www.plaguicidasdecentroamerica. una.ac.cr (Consultado 26 enero 2013).

Gómez, O. 2004. Estudio detallado de suelos de la microcuenca Plantón-Pacayas, Pacayas de Alvarado, Cartago. Documento Técnico No. 1. Proyecto Plantón-Pacayas. Instituto Nacional de Innovación y Transferencia en Tecnología Agropecuaria (INTA), San José, Costa Rica.

MAG (Ministerio de Agricultura y Ganadería). 1991. Aspectos técnicos sobre cuarenta y cinco cultivos agrícolas de Costa Rica. MAG. San José, Costa Rica.

Montero, Z., C. García, L. Salazar, R. Valverde, y L. Gómez. 2007. Detección de Meloidogyne incognita en tubérculos de papa en Costa Rica. Agron. Costarricense 31(1):77-84.

Murphy, K. 1997. Innovative cropping systems can replace hazardous pesticides. J. Pestic. Reform 17(4):2-7.

PIMA (Programa Integral de Mercadeo Agropecuario). 2013. Tendencias del consumo de frutas, hortalizas, pescado y mariscos en las familias de Costa Rica. http:// pima.go.cr/AP/CM/PG5038L1/PIMA-PROGRAMAINTEGRAL-DE-MERCADO-AGROPECUARIO. aspx (Consultado 22 mayo 2014).

PAN (Pesticide Action Network). 2007. Pesticide data base. California pesticide use. Pesticide use in potatoes. http://www.pesticideinfo.org/DS.jsp?sk=14013 (Consultado 28 ene. 2012).

PAN (Pesticide Action Network). sf. Pesticide data base search. http://www.pesticideinfo.org/Search_ Chemicals.jsp (Consultado 20 ene. 2014).
PAN-UK (Pesticide Action Network - United Kingdom). 2009. The list of lists. A catalogue of lists of pesticides identifying those associated with particularly harmful health or environmental impacts. 3era ed. London, UK. 26 p. http://www.pan-europe.info/Campaigns/ pesticides/documents/cut_off/list $\% 20$ of $\% 20$ lists.pdf (Consultado 14 oct. 2011).

Pumisacho, M., y J. Velásquez. 2009. Manual del cultivo de papa para pequeños productores. INIAP, COSUDE, Quito, Ecuador.

Ramírez, F., F. Chaverri, E. de la Cruz, C. Wesseling, L. Castillo, y V. Bravo. 2009. Importación de plaguicidas en Costa Rica: periodo 1977-2006. Serie Informes Técnicos, Instituto Regional de Estudios en Sustancias Tóxicas (IRET), Nº6, Universidad Nacional, Heredia, Costa Rica.

Reuters. 2009. McDonalds initiates review to reduce pesticides in potato production. http://www. beyondpesticides.org/dailynewsblog/?p=1532 (Consultado 28 ene. 2010).

SFE (Servicio Fitosanitario del Estado). 2012. Límites máximos de residuos. http://www.sfe.go.cr/ agroquimicos/lmr.html (Consultado 30 enero 2013).

SEPSA (Secretaría Ejecutiva de Planificación Sectorial Agropecuaria). 2011. Boletín Estadístico Agropecuario $N^{\circ} 21$. Área de Estadísticas Económicas e Información, San José, Costa Rica.

Vásquez, V., M. Montero, y C. Riveral. 2005. Incidencia y distribución altitudinal de 13 virus en cultivos de Solanum tuberosum (Solanaceae) en Costa Rica. Rev. Biol. Trop. 54:1135-1141. 
